\title{
CLINICAL-ALIMENTARY TRACT
}

\section{Peptic Ulcer and Bleeding Events Associated With Rofecoxib in a 3-Year Colorectal Adenoma Chemoprevention Trial}

\author{
ANGEL LANAS, ${ }^{*}$ JOHN A. BARON, ${ }^{\ddagger}$ ROBERT S. SANDLER, ${ }^{\S}$ KEVIN HORGAN," JIM BOLOGNESE," BETTINA OXENIUS," \\ HUI QUAN," DOUGLAS WATSON," TOMAS J. COOK," ROBERT SCHOEN," CAROL BURKE," SUSAN LOFTUS," \\ YARON NIV, ${ }^{* \star}$ ROBERT RIDELL, ${ }^{\neq \ddagger}$ DION MORTON, ${ }^{\S}$ and ROBERT BRESALIER ${ }^{\|l\|}$
}

*Department of Medicine, University Clinic Hospital, Instituto Aragones de Ciencias de la Salud (CIBER HEPAD) Zaragoza, Spain; ${ }^{\star}$ Departments of Medicine and Community and Family Medicine, Dartmouth Medical School, Hanover, New Hampshire; ${ }^{\S}$ Department of Medicine, University of North Carolina, Chapel Hill, North Carolina; "Merck Research Laboratories, West Point, Pennsylvania; "Department of Medicine, University of Pittsburgh School of Medicine, Pittsburgh, Pennsylvania; \#Department of Gastroenterology, the Cleveland Clinic Foundation, Cleveland, Ohio; **Department of Gastroenterology, Rabin Medical Center, Petah Tiqva, Israel;

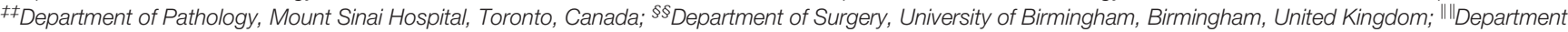
of Gastrointestinal Medicine and Nutrition, University of Texas, MD Anderson Cancer Center, Houston, Texas

See editorial on page 790.

Background \& Aims: Our aim was to establish the incidence of symptomatic upper gastrointestinal ulcers, ulcer perforation, ulcer obstruction, or bleeding episodes (PUBs) associated with the use of selective cyclooxygenase- 2 inhibitors at standard clinical doses compared with placebo. We report here on the PUB outcomes associated with the use of rofecoxib $25 \mathrm{mg}$ in a 3-year, multicenter, doubleblind, placebo-controlled trial designed to determine the effect of rofecoxib on the risk of recurrent neoplastic polyps of the colon. Methods: A total of 2587 patients with a history of colorectal adenomas underwent randomization to $25 \mathrm{mg}$ /day of rofecoxib or to placebo. Investigator-reported PUBs were adjudicated by an external blinded committee. Kaplan-Meier and Cox proportional hazards techniques were used to estimate incidence and relative risks of PUBs in an intention-to-treat analysis. Results: Patients assigned to rofecoxib had a higher incidence of confirmed PUBs than those randomized to placebo $(.88 \mathrm{vs} .18$ events per 100 patient-years; relative risk, $4.9 ; 95 \%$ confidence interval, 1.98-14.54). The incidence of confirmed complicated PUBs (ulcer perforation, obstruction, or bleeds) was low, but was numerically higher in the rofecoxib than in the placebo group (.23 vs .06 events per 100 patient-years; relative risk, 3.8 ; $95 \%$ confidence interval, $.72-37.46 ; P=.14)$. Rofecoxib increased the incidence of confirmed PUBs vs placebo in both low-dose aspirin users and nonusers. Conclusions: Among patients with a history of colorectal adenomas, the long-term use of $25 \mathrm{mg} /$ day of rofecoxib was associated with an increased risk of clinically relevant upper gastrointestinal events when compared with placebo.
$\mathrm{N}$ onsteroidal anti-inflammatory drugs (NSAIDs) are used widely for the treatment of pain and inflammation in various rheumatic conditions, but may cause gastrointestinal (GI) ulceration and bleeding, presumably as a result of inhibition of the cyclooxygenase-1 (COX1)-mediated production of prostaglandins. Selective inhibitors of COX-2 were developed to provide analgesic and anti-inflammatory efficacy similar to nonselective COX inhibitors, but with reduced upper-GI side effects. ${ }^{1}$

Several placebo-controlled endoscopy studies of osteoarthritis or rheumatoid arthritis patients have reported that the use of COX-2-selective inhibitors is associated with rates of endoscopically determined gastroduodenal ulcers lower than in patients taking nonselective NSAIDs $^{2-5}$ and either similar ${ }^{2-4}$ or slightly higher ${ }^{5}$ than observed in patients taking placebo. Two long-term (12mo) outcome studies, VIGOR 6 (VIOXX Gastrointestinal Outcomes Research) and Therapeutic Arthritis Research and Gastrointestinal Event Trial, 7 have shown that both rofecoxib and lumiracoxib were associated with reduced risks of upper-GI complications and symptomatic gastroduodenal ulcers in comparison with nonselective NSAIDs. However, a celecoxib outcomes study, Celecoxib Long-term Arthritis Safety Study, reported an incidence of upper-GI complications similar to that observed with traditional NSAIDs, although when upper-GI complications were combined with symptomatic peptic ulcers, celecoxib also was superior to nonselective NSAIDs. ${ }^{8}$ In a more recent short-term (12-wk) trial that compared lower

Abbreviations used in this paper: APPROVe, Adenomatous Polyp Prevention On Vioxx; Cl, confidence interval; COX, cyclooxygenase; GI, gastrointestinal; PUBs, symptomatic gastroduodenal ulcers, gastroduodenal ulcer perforation, obstruction or bleeds; PPI, proton pump inhibitor; VIGOR, VIOXX Gastrointestinal Outcomes Research.

(1) 2007 by the AGA Institute 0016-5085/07/\$32.00 doi:10.1053/j.gastro.2006.11.012 
doses of celecoxib with traditional NSAIDs, ${ }^{9}$ patients taking celecoxib had a lower rate of ulcer complications and upper gastrointestinal events than those taking traditional NSAIDs.

The relevance of those findings to clinical practice is unclear because the doses of COX-2 inhibitors in these trials, ${ }^{6-8}$ but not the doses of the NSAID comparators, were higher than those routinely used clinically. Furthermore, a coherent understanding of the data from the endoscopy studies and the outcomes studies has not been possible because of the lack of a placebo group in the outcomes studies. ${ }^{6-9}$ Also, information on the incidence of GI side effects associated with the use of these compounds for other indications in patients without musculoskeletal diseases (eg, cancer prevention) is limited.

The Adenomatous Polyp Prevention On Vioxx (APPROVe) trial was designed to evaluate the hypothesis that adenomatous polyp recurrence would be reduced in patients receiving rofecoxib, a selective COX-2 inhibitor, for 3 years. Investigator-reported symptomatic upper-GI ulcers, ulcer perforation, obstruction, or bleeds (PUBs) were adjudicated by an independent committee, and all safety data were monitored regularly by an external safety monitoring committee. We report here the upper-GI side effects observed in the study. The primary efficacy and tolerability data from this study, and the cardiovascular outcomes, are the subject of separate reports. ${ }^{10,11}$

\section{Materials and Methods}

The design of the study has been described in detail elsewhere. ${ }^{10,11}$ In brief, enrollment occurred from February 2000 to November 2001 at 108 centers in 29 countries. Men and women at least 40 years old were eligible if they had undergone removal of at least 1 histologically confirmed large-bowel adenoma within 12 weeks of study entry. Only patients who were not anticipated to need chronic NSAID therapy (including analgesic doses of aspirin) during the study and/or patients who had not been taking NSAIDs on a chronic basis, defined as 7 or more total days of each month for the 2 consecutive months before the screening visit, were enrolled. Low-dose aspirin for cardiovascular protection ( $\leq 100 \mathrm{mg} /$ day) was allowed, although limited to a maximum of $20 \%$ of patients at baseline, to minimize the ability of low-dose aspirin to mask the possible chemopreventive effects of rofecoxib. Individuals with a history of ulcer or dyspepsia were eligible. Patients with uncontrolled hypertension $(>165 / 95 \mathrm{~mm} \mathrm{Hg})$, angina or congestive heart failure at rest or with minimal activity, evidence of occult GI bleeding, or history of small- or large-bowel resection were excluded.

Written informed consent was obtained from all patients enrolled. The study was approved by the institutional review board for each center. The active treatment period was preceded by a 6 -week single-blind placebo run-in to assess patient compliance with study medication. Patients who took at least $80 \%$ of their tablets during the placebo run-in were assigned randomly to receive either 1 rofecoxib $25-\mathrm{mg}$ tablet or 1 identicalappearing placebo tablet daily for 3 years. The computerderived randomization was stratified by clinical center and low-dose aspirin use, with a blocking factor of 2 . Patients, investigators, and study-sponsor personnel involved in study monitoring were blinded to the treatment allocation schedule. Follow-up evaluation continued until 2 weeks after the last dose of study treatment. There were in-person clinic visits at randomization and at weeks $4,17,35,52,69,86,104,121,138,156$, and after discontinuation of treatment. At each visit, patients were asked if they experienced any symptoms or side effects; compliance also was monitored. Vital signs were measured at each clinic visit during the study.

Before the start of the trial, a previously described standard procedure was instituted for investigators to report PUBs for adjudication. ${ }^{10}$ The definition of a PUB event in this trial was identical to that reported previously in GI outcome studies with rofecoxib, ${ }^{6}$ and included either the diagnosis of a gastroduodenal symptomatic ulcer, or the occurrence of ulcer perforation, nonmalignant ulcer gastric outlet obstruction, or upper-GI bleeding. Clinical documentation of investigator-reported candidate PUBs was reviewed by a blinded, external adjudication committee. The committee determined whether a suspected PUB was confirmed (confirmed PUB), and whether it was a complicated event by virtue of the presence of clinically significant upper-GI bleeding, obstruction, or perforation, using predefined criteria (confirmed complicated PUB). Confirmed PUBs, the primary GI end point, were included in the analysis. Data presented here include events occurring on study drug and up to 14 days after the last dose. An independent external safety monitoring board met periodically to review the safety data provided by an unblinded statistician who was not otherwise involved in the study.

The clinical investigators also recorded more minor GI adverse events, including episodes of dyspepsia, abdominal pain, and upper-abdominal pain among many others; however, these were not adjudicated. Discontinuation because of a GI system adverse experience including abdominal pain, was prespecified for comparison.

\section{Statistical Analysis}

The analysis, performed using SAS software version 8.2 (SAS Institute, Cary, NC), included all randomized patients who took at least 1 dose of study medication. We used a Cox proportional hazards model with treatment as the only factor to compute hazard ratios (relative risks) and 95\% confidence intervals (CIs), and Kaplan-Meier techniques to estimate cumulative proportions of patients experiencing confirmed PUBs over time. Subgroup analyses for confirmed PUBs were performed to assess the uniformity of treatment effect across sub- 
Table 1. Patient Characteristics

\begin{tabular}{|c|c|c|}
\hline & \multicolumn{2}{|c|}{ Treatment group } \\
\hline & $\begin{array}{l}\text { Rofecoxib } \\
(\mathrm{N}=1287)\end{array}$ & $\begin{array}{c}\text { Placebo } \\
(\mathrm{N}=1300)\end{array}$ \\
\hline Male, $\mathrm{n}(\%)$ & $804(62.5)$ & 805 (61.9) \\
\hline Mean age, $(y)$ & 59.4 & 59.4 \\
\hline Ulcer history, n (\%) & $93(7.2)$ & $94(7.2)$ \\
\hline Alcohol user at baseline, $\mathrm{n}(\%)$ & $773(60.1)$ & $764(58.8)$ \\
\hline Caffeine user at baseline, $\mathrm{n}(\%)$ & $1167(90.7)$ & $1168(89.8)$ \\
\hline Ex/current tobacco user at baseline, $\mathrm{n}(\%)$ & $776(60.3)$ & $774(59.5)$ \\
\hline Low-dose ( $\leq 100 \mathrm{mg} /$ day) aspirin user at baseline, $\mathrm{n}(\%)$ & $213(16.6)$ & $204(15.7)$ \\
\hline Low-dose aspirin user during trial, $\mathrm{n}(\%)^{a}$ & $233(18.1)$ & $236(18.2)$ \\
\hline Any dose aspirin user during trial, $\mathrm{n}(\%)^{b}$ & $245(19.0)$ & $245(18.8)$ \\
\hline Antisecretory drug user at baseline, $\mathrm{n}(\%)^{c}$ & $266(20.7)$ & $275(21.2)$ \\
\hline Antisecretory drug user during trial, $\mathrm{n}(\%)^{d}$ & $454(35.3)$ & $432(33.2)$ \\
\hline Proton pump inhibitor user at baseline, $\mathrm{n}(\%)^{e}$ & $185(14.4)$ & $205(15.8)$ \\
\hline Proton pump inhibitor user during trial, $\mathrm{n}(\%)^{f}$ & $354(27.5)$ & $341(26.2)$ \\
\hline
\end{tabular}

${ }^{a}$ Defined as a patient who took $\leq 100 \mathrm{mg} /$ day aspirin for at least $50 \%$ of the time while on study therapy and did not start any of these medications after a PUB event.

${ }^{b}$ Defined as a patient who took any dose of aspirin or aspirin-containing products for at least $50 \%$ of the time while on study therapy and did not start any of these medications after a PUB event.

'Defined as a patient who took $\geq 1$ dose of $\mathrm{H} 2$-blocker or PPI at baseline.

${ }^{d}$ Defined as a patient who took $\geq 1$ dose of H2-blocker or PPI while on study therapy.

eDefined as a patient who took $\geq 1$ dose of PPI before randomization.

fDefined as a patient who took $\geq 1$ dose of PPI while on study therapy.

groups (ie, interactions). There were no stratification factors or covariates in the analysis models because the number of events was small. Demographic and clinical data also were tested one at a time to assess whether the variable was a significant risk factor for PUBs in the entire population of the study. Interaction assessment was not reported if data were too sparse (eg, 0 events in some of the groups). PUB events were monitored up until 14 days after the last dose of study medication. The last date a patient took any study medication was on October 24, 2004. The last reported PUB event occurred on September 29, 2004. All reported PUB events were adjudicated and the last date that cases were adjudicated was on December 9, 2004. The data reported here are those available to the authors as of April 27, 2006.

\section{Results}

\section{Demographics and Characteristics of Participants}

A total of 3260 patients were screened for inclusion in the study, 2612 were considered eligible and 2587 were randomized to rofecoxib $25 \mathrm{mg}$ or placebo; all took at least one dose of study medication, and therefore all 2587 were included in the analysis. The treatment groups were similar with regard to measured baseline characteristics including age, sex, and GI risk factors (Table 1).

At baseline, low-dose aspirin ( $\leq 100 \mathrm{mg} /$ day) was taken by $16.6 \%$ of patients randomized to rofecoxib and $15.7 \%$ of those assigned to placebo. The use of other medications, including antisecretory agents such as $\mathrm{H}_{2}$-blockers or proton pump inhibitors (PPIs), both at baseline and during the study, was similar in the 2 groups (Table 1). At the time the study was terminated because of increased cardiovascular risk with long-term use of rofecoxib (September 2004), 870 patients in the rofecoxib group and 980 patients in the placebo group had completed the 3 years of study treatment, with a mean on-drug exposure time of 2.30 years in the rofecoxib group and 2.48 years in the placebo group.

\section{UPper-GI PUBs}

A total of 27 patients in the rofecoxib group had a confirmed PUB (20 uncomplicated and 7 complicated) during 3067 patient-years of follow-up evaluation (.88 events per 100 patient-years; $95 \%$ CI, $0.58-1.28$ ). In the placebo group there were 6 patients with PUBs (4 uncomplicated

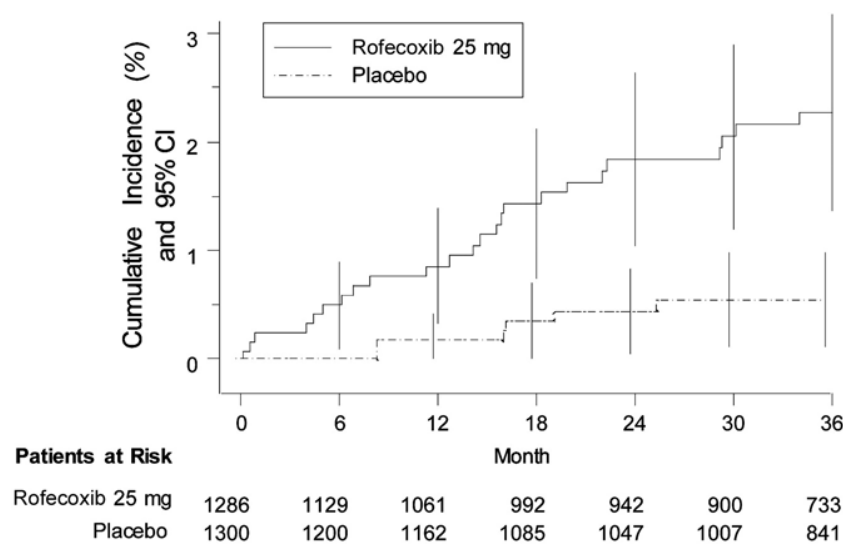

Figure 1. Cumulative incidence of confirmed PUBS with rofecoxib 25 $\mathrm{mg} /$ day and placebo over time. 


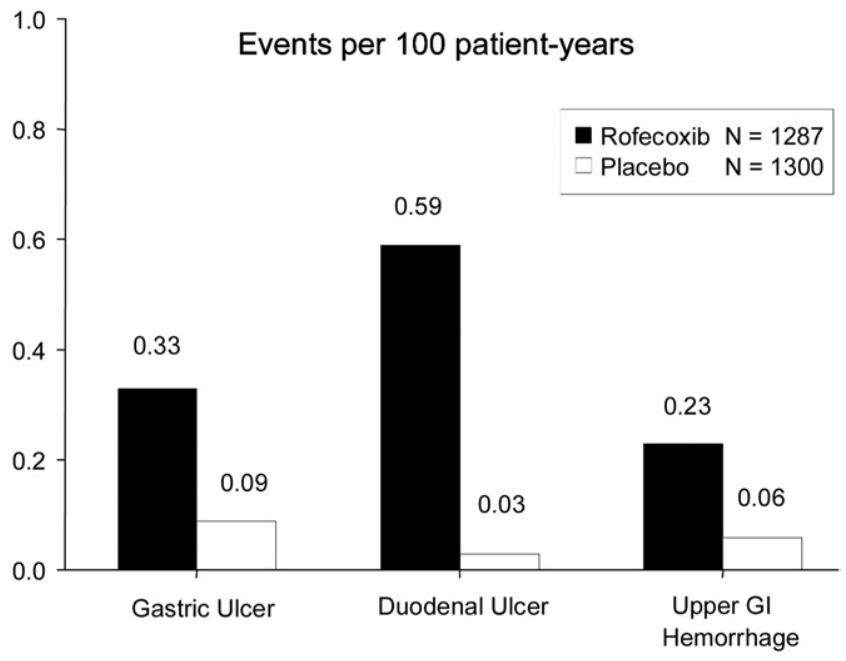

Figure 2. Types of confirmed PUBs with rofecoxib $25 \mathrm{mg} /$ day and placebo. The gastric or duodenal ulcer event rate include both symptomatic uncomplicated ulcers and complicated ulcers. Complicated events (7 in the rofecoxib group and 2 in the placebo group) were all upper Gl bleeding events and included 3 cases of gastric ulcer and 1 of duodenal ulcer in the rofecoxib group; no gastric or duodenal ulcer cases were identified in the 2 cases of upper Gl bleeding in the placebo group. Twenty patients in the refecoxib group had uncomplicated symptomatic ulcers (4 patients had gastric ulcers, 14 had duodenal ulcers, and 2 patients had both gastric and duodenal ulcers. Four patients in the placebo group had uncomplicated symptomatic ulcers ( 3 patients had gastric ulcers and 1 had a duodenal ulcer). There were 2 rofecoxib patients that had both complicated and uncomplicated PUBs. They are not counted in the 20 patients with uncomplicated symptomatic ulcers.

and 2 complicated) during 3342 patient-years of follow-up evaluation (.18 events per 100 patient-years; 95\% CI, .07-.39; absolute difference: .70 events per 100 patient-years; $95 \% \mathrm{CI}$, $0.34-1.06)$. The relative risk was 4.9 (95\% CI, $1.98-14.5$ ) (Figure 1). The risk of both duodenal ulcers and gastric ulcers was increased in the rofecoxib group, although the increase seemed greater for the former (Figure 2). The rates of confirmed complicated PUBs were .23 (95\% CI, .09-.43) and .06 (95\% CI, .01-.22) events per 100 patient-years in the rofecoxib and placebo groups, respectively $(P=.14)$ (absolute difference, .17 events per 100 patient-years; $95 \%$ CI, -. .02 to .35). The corresponding rates of confirmed symptomatic uncomplicated ulcers were .65 (95\% CI, .40-1.01) and .12 (95\% CI, .03-.31) per 100 patient-years $(P<.001)$ (absolute difference, .53 events per 100 patient-years; 95\% CI, 0.22 .84).There were no deaths associated with the PUB events. One patient who was taking placebo died of disseminated intravascular coagulation, renal failure, and hepatic failure 10 days after colonoscopy complicated by colonic perforation, but this event was not counted as a PUB in the analysis because it was located in the large bowel.

Confirmed PUBs were more than 3 times more frequent in the rofecoxib treatment group than in the placebo group both among those who did not use low-dose aspirin during the trial $(P=.005)$ and among those who did use aspirin either at baseline or during the study $(P=.014)$ (Table 2$)$. Further subgroup analyses were performed to test whether there were differences in the relative risk (rofecoxib vs placebo) of confirmed PUBs according to the presence of potential modifying risk factors such as age, sex, race, caffeine or alcohol use, and smoking. There were no significant treatment-by-subgroup interactions except for alcohol use, which seemed to increase the PUB risk among rofecoxib subjects (Table 3 ).

In this study, ulcer history was a risk factor for PUBs relative risk (RR, 3.32; 95\% CI, 1.36-8.09), but the data were too sparse to determine whether ulcer history increased the PUB risk among subjects taking rofecoxib relative to placebo. Data regarding the use of either $\mathrm{H} 2$-receptor antagonists or PPIs and rates of PUBs in our population are reported in Table 3.

Table 2. Summary of Rates and Relative Risks for Confirmed PUBs According to Aspirin Use

\begin{tabular}{|c|c|c|c|c|c|c|c|}
\hline & \multicolumn{3}{|c|}{ Rofecoxib $25 \mathrm{mg}(\mathrm{N}=1287)$} & \multicolumn{3}{|c|}{ Placebo $(\mathrm{N}=1300)$} & \multirow{2}{*}{$\begin{array}{l}\text { Treatment Comparison } \\
\text { Relative risk }(95 \% \mathrm{Cl})\end{array}$} \\
\hline & $\begin{array}{l}\text { No. at } \\
\text { risk }\end{array}$ & $\begin{array}{l}\text { No. of } \\
\text { events }\end{array}$ & $\begin{array}{c}\text { Rate/100 patient-yr } \\
(95 \% \mathrm{Cl})\end{array}$ & $\begin{array}{l}\text { No. at } \\
\text { risk }\end{array}$ & $\begin{array}{l}\text { No. of } \\
\text { events }\end{array}$ & $\begin{array}{l}\text { Rate/100 patient-yr } \\
(95 \% \mathrm{Cl})\end{array}$ & \\
\hline \multicolumn{8}{|c|}{$\begin{array}{l}\text { Low-dose ( } \leq 100 \mathrm{mg} / \text { day) } \\
\text { aspirin user at baseline }\end{array}$} \\
\hline No & 1074 & 20 & $.78(.47-1.20)$ & 1096 & 6 & $.21(.08-46)$ & $3.67(1.42-11.17)$ \\
\hline Yes & 213 & 7 & $1.43(.57-2.94)$ & 204 & 0 & $.00(.00-73)$ & Undefined \\
\hline \multicolumn{8}{|c|}{$\begin{array}{l}\text { Low-dose aspirin user } \\
\text { during trial }{ }^{a}\end{array}$} \\
\hline No & 1054 & 18 & $.71(.42-1.13)$ & 1064 & 6 & $.22(.08-.48)$ & $3.25(1.24-10.00)$ \\
\hline Yes & 233 & 9 & $1.66(.76-3.16)$ & 236 & 0 & $.00(.00-.61)$ & Undefined \\
\hline \multicolumn{8}{|c|}{$\begin{array}{l}\text { Any dose aspirin user } \\
\text { during } \text { trial }^{b}\end{array}$} \\
\hline No & 1043 & 18 & $.72(.43-1.14)$ & 1055 & 6 & $.22(.08-48)$ & $3.25(1.24-10.01)$ \\
\hline Yes & 244 & 9 & $1.59(.73-3.01)$ & 245 & 0 & $.00(.00-58)$ & Undefined \\
\hline
\end{tabular}

aDefined as a patient who took $\leq 100 \mathrm{mg}$ of aspirin or aspirin-containing products for at least $50 \%$ of the time while on study therapy and did not start any of these medications after a PUB event.

${ }^{b}$ Defined as a patient who took any dose of aspirin or aspirin-containing products for at least $50 \%$ of the time while on study therapy and did not start any of these medications after a PUB event. 
Table 3. Summary of Rates and Relative Risks for Confirmed PUBs According to Different Risk Factors

\begin{tabular}{|c|c|c|c|c|c|c|c|c|}
\hline & \multicolumn{3}{|c|}{ Rofecoxib 25 mg $(\mathrm{N}=1287)$} & \multicolumn{3}{|c|}{ Placebo $(\mathrm{N}=1300)$} & \multicolumn{2}{|c|}{ Treatment comparison } \\
\hline & $\begin{array}{l}\text { No. at } \\
\text { risk }\end{array}$ & $\begin{array}{l}\text { No. of } \\
\text { events }\end{array}$ & $\begin{array}{c}\text { Rate/100 patient-year } \\
(95 \% \mathrm{Cl})\end{array}$ & $\begin{array}{l}\text { No. at } \\
\text { risk }\end{array}$ & $\begin{array}{l}\text { No. of } \\
\text { events }\end{array}$ & $\begin{array}{c}\text { Rate/100 patient-year } \\
(95 \% \mathrm{Cl})\end{array}$ & Relative risk $(95 \% \mathrm{Cl})$ & $\begin{array}{l}P \text { value, subgroup-by- } \\
\text { treatment interaction }\end{array}$ \\
\hline Age, $(y)$ & & & & & & & & .684 \\
\hline$<65$ & 903 & 17 & $.77(.45-1.23)$ & 914 & 3 & $.13(.03-37)$ & $6.11(1.77-32.52)$ & \\
\hline$\geq 65$ & 384 & 10 & $1.16(.56-2.14)$ & 386 & 3 & $.31(.06-91)$ & $3.75(.96-21.19)$ & \\
\hline Sex $x^{a}$ & & & & & & & & .331 \\
\hline Male & 804 & 22 & $1.13(.71-1.71)$ & 805 & 4 & $.19(.05-.48)$ & $5.99(2.03-23.90)$ & \\
\hline Female & 483 & 5 & $45(.15-1.05)$ & 495 & 2 & $.16(.02-.59)$ & $2.74(.45-28.73)$ & \\
\hline Race $^{a}$ & & & & & & & & .082 \\
\hline White & 1082 & 20 & $77(.47-1.19)$ & 1086 & 2 & $.07(.01-.26)$ & $10.78(2.62-95.09)$ & \\
\hline Other & 205 & 7 & $1.51(.61-3.11)$ & 214 & 4 & $.74(.20-1.90)$ & $2.04(.52-9.48)$ & \\
\hline Caffeine user & & & & & & & & .224 \\
\hline No & 119 & 3 & $1.03(.21-3.01)$ & 132 & 2 & $.56(.07-2.04)$ & $1.83(.21-21.87)$ & \\
\hline Yes & 1167 & 24 & $87(.55-1.29)$ & 1168 & 4 & $.13(.04-.34)$ & $6.47(2.22-25.66)$ & \\
\hline Alcohol user & & & & & & & & .028 \\
\hline No & 505 & 7 & $.59(.24-1.21)$ & 527 & 5 & $.38(.12-.89)$ & $1.55(.42-6.19)$ & \\
\hline Yes & 773 & 20 & $1.08(.66-1.67)$ & 764 & 1 & $.05(.00-.28)$ & 21.66 (3.46-897.64) & \\
\hline Current cigarette user & & & & & & & & .329 \\
\hline No & 1007 & 16 & $66(.38-1.07)$ & 1015 & 5 & $.19(.06-.44)$ & $3.45(1.21-12.05)$ & \\
\hline Yes & 280 & 11 & $1.74(.87-3.11)$ & 285 & 1 & $.14(.00-.78)$ & $12.49(1.82-537.66)$ & \\
\hline History of upper-Gl ulcers ${ }^{a}$ & & & & & & & & $b$ \\
\hline No & 1194 & 20 & $70(.43-1.08)$ & 1206 & 6 & $.19(.07-.42)$ & 3.61 (1.40-11.00) & \\
\hline Yes & 93 & 7 & $3.47(1.39-7.15)$ & 94 & 0 & $.00(.00-1.55)$ & (Undefined) & \\
\hline Use of H2-RA before PUB event & & & & & & & & .093 \\
\hline No & 1114 & 22 & $83(.52-1.26)$ & 1142 & 3 & $.10(.02-.30)$ & $8.16(1.60-30.50)$ & \\
\hline Yes & 173 & 5 & $1.16(.38-2.71)$ & 158 & 3 & $.73(.15-2.14)$ & $1.59(.31-10.24)$ & \\
\hline Use of PPI before PUB event & & & & & & & & .832 \\
\hline No & 951 & 19 & $.85(.51-1.32)$ & 970 & 5 & $20(.06-.47)$ & $4.23(1.53-14.49)$ & \\
\hline Yes & 336 & 8 & $97(.42-1.92)$ & 330 & 1 & $.12(.00-.44)$ & $8.24(1.10-365.71$ & \\
\hline Region ${ }^{a}$ & & & & & & & & $b$ \\
\hline US & 660 & 10 & $.64(.31-1.18)$ & 669 & 0 & $.00(.00-.22)$ & (Undefined) & \\
\hline Non-US & 627 & 17 & $1.13(.66-1.81)$ & 631 & 6 & $.36(.13-.78)$ & 3.17 (1.19-9.81) & \\
\hline
\end{tabular}

aThese variables were found to be associated as risk factors for PUBs.

${ }^{b}$ Data were too sparse for interaction assessment. 


\section{Other GI Adverse Events}

Reports of other GI adverse events were collected during the trial but these were not adjudicated. Treatment discontinuation because of a gastrointestinal adverse experience occurred in $2.95 \%$ (95\% CI, 2.03-3.88) of patients taking rofecoxib and $2.23 \%$ (95\% CI, 1.43-3.04) of patients taking placebo $(P=.27)$. Among other specific side effects commonly associated with NSAID use such as dyspepsia, abdominal pain, or upper abdominal pain, ${ }^{12}$ the proportion of patients who reported having one or more of these side effects was $18.6 \%$ in the rofecoxib group and $18.5 \%$ in the placebo arm.

\section{Discussion}

In this randomized, placebo-controlled adenoma chemoprevention trial, we found that, among patients with a history of colorectal adenomas, long-term treatment with standard doses of the COX-2-selective inhibitor rofecoxib was associated with an increased risk of confirmed PUBs compared with placebo. Our findings are supported by results from a previous smaller longterm trial in elderly patients with mild cognitive impairment that also reported an increase in upper-GI events for rofecoxib vs placebo. ${ }^{13}$

It is notable, however, that the absolute rate of PUBs in patients taking rofecoxib was low in this study, lower than in the VIGOR trial, ${ }^{6}$ and much lower than that ascribed to conventional NSAIDs. ${ }^{6-8}$ The reasons for the difference in rates found in patients taking rofecoxib in this study and in the VIGOR trial are not clear, but the 3 main differences between the 2 studies are the dose (50 $\mathrm{mg} /$ day in VIGOR vs $25 \mathrm{mg}$ /day in APPROVe), the nature of the baseline disease (rheumatoid arthritis in VIGOR vs a much healthier population in this study), and the use of PPIs by some patients in the APPROVe study. Other potential factors such as naive vs chronic users of NSAIDs, or concomitant low-dose aspirin, might have tended to increase PUB rates in APPROVe.

In contrast to previous experience in patients taking nonselective NSAIDs, rofecoxib was associated with a greater increase of duodenal ulcers than of gastric ulcers. This anatomic pattern of ulcer occurrence is consistent with similar findings obtained in previous studies with rofecoxib, including the VIGOR trial ${ }^{6}$ and Alzheimer disease studies (Alise Reicin, personal communication, March 2006). Because Helicobacter pylori infection is the main factor involved in the pathogenesis of duodenal ulcers and previous analyses have reported that $H$ pylori infection is a risk factor for peptic ulcer events in patients taking rofecoxib, ${ }^{14}$ it would have been of interest to know the $H$ pylori status of our patients. Unfortunately, this was not evaluated systematically in this trial.

The only factor identified that significantly modified the relationship between rofecoxib use and PUB risk was alcohol intake. Patients who used alcohol had a rofecoxib rela- tive risk for developing PUBs that was much higher than those who did not drink alcohol. Alcohol has been identified as a risk factor for upper-GI bleeding in patients taking aspirin and NSAIDs in some observational studies, ${ }^{15,16}$ but other studies including randomized controlled trials did not confirm this. ${ }^{14,17}$ On the other hand, alcohol may prolong the bleeding time after NSAID/aspirin use, ${ }^{18}$ but there are no data regarding a possible interaction with coxib use. Furthermore, it must be noted that the definition of alcohol use in this and other studies ${ }^{15-18}$ is vague and includes patients using different types of alcohol and different doses from infrequent to heavy use.

Dyspepsia is a frequent side effect of NSAID use. ${ }^{1}$ Coxib use has been associated with a lower frequency of this side effect when compared with nonselective NSAIDs. ${ }^{12}$ In this study, the frequency of reported dyspepsia and/or abdominal pain (including upper-abdominal pain) by the investigators was similar in patients and controls, findings consistent with the better profile (coxibs have a lower incidence of dyspepsia when compared to nonselective NSAIDs) described for coxibs than for nonselective NSAIDs.

Our study had limitations that should be taken into account when considering the clinical implications and conclusions obtained. Although the study procedures, event adjudication, and predefined analysis plan addressed GI outcomes, the study was not designed primarily for this analysis. As a result, we may not have optimally identified and categorized all potential GI events that occurred during the trial. A second important limitation is that patients who usually take COX-2-selective inhibitors may be older and have a higher risk of GI complications than our patients, ${ }^{12,19}$ differences that may affect the risk of PUBs and complications when taking this class of drugs. Finally, the study did not compare rofecoxib users with patients taking other analgesics, for example, acetaminophen. Except for prevention studies, such as the one described here, most patients would take a COX inhibitor for some painful condition (eg, arthritis). The results of the present study show that the risk of upper-GI toxicity is greater with COX-2-selective inhibitors than with no therapy (placebo), but that the absolute risk is low. Physicians and their patients should weigh the potential risks and benefits of the use of this class of drugs.

\section{Appendix}

The Steering Committee for the APPROVe trial consisted of John A. Baron, MD (Chair), Robert S. Bresalier, MD, Robert S. Sandler, MD, Robert Riddell, MD, Dion Morton, MD, Angel Lanas, MD, Bettina Oxenius MD,* James A. Bolognese MStat,* and Kevin Horgan, MD.*

The external safety monitoring board consisted of James Neaton, $\mathrm{PhD}$ (Chair), University of Minnesota;

\footnotetext{
*Nonvoting member.
} 
Marvin A. Konstam, MD, New England Medical Center; David Bjorkman, MD, University of Utah Health Sciences Center; Richard Logan MD, University of Nottingham School of Community Health Sciences; and Hui Quan, $\mathrm{PhD}, *$ Merck Research Laboratories.

The APPROVe Trial included the following investigators: M. Aguilar, Clinica Aguilar Bonilla, San Jose, Costa Rica; P. Angus, Austin \& Repatriation Medical Centre, Heidelberg, Australia; N. Arber, Tel Aviv Sourasky Medical Center, Tel Aviv, Israel; J. M. P. Badia, Hospital Clinic I Provincial, Barcelona, Spain; R. D. Baerg, Tacoma Digestive Disease Center, Tacoma, Washington; H. Baistrocchi, Unidad de Aparato Digestivo Julio Dante Baistrocchi, Cordoba, Argentina; M. L. Barclay, Christchurch Hospital, Christchurch, New Zealand; C. Beglinger, University of Basel, Basel, Switzerland; G. Bianchi-Porro, Ospedale Luigi Sacco, Milano, Italy; T. Bolin, Prince of Wales Hospital, Randwick, Australia; R. M. Bostick, Palmetto Health South Carolina Cancer Center, Columbia, South Carolina; J. Bradbury, University Hospital Birmingham, England; R. S. Bresalier, A. A. Dekovich, T. Ben-Menachem, S. K. Batra, Henry Ford Hospital, Detroit, Michigan; E. Bruun, J. Christiansen, Amtssygehuset i Herlev, Herlev, Denmark; C. Burke, Cleveland Clinic Foundation, Cleveland, Ohio; E. Butruk, Akademia Medyczna w Warszawie, Warsaw, Poland; L. Capurso, Azienda Ospedaliera San Filippo, Roma, Italy; J. P. Cello, San Francisco General Hospital, San Francisco, California; M. Chapman, Good Hope Hospital, Sutton Coldfield, England; S. Chaussade, Hospital Cochin SaintJacques, Paris, France; D. P. Cleland, Montreal General Hospital, Montreal, Canada; G. Costamagna, Universita Cattolica del Sacro Cuore, Di Clinica Chirurgica, Rome, Italy; P. Crone, Kobenhavns Amtssygehus i Glostrup, Glostrup, Denmark; E. V. Cutsem, Universitaire Ziekenhuizen KU, Leuven, Belgium; G. R. D’Haens, Imeldaziekenhuis, Bon Heiden, Belgium; W. Dekker, J. Ferwerda, Kennemer Gasthuis, Haarlem, Netherlands; E. Dominguez-Munoz, Hospital de Conxo, La Coruna, Spain; D. S. Eskreis, R. E. Tepper, Long Island Clinical Research Associates, Great Neck, New York; R. Estela, Hospital Clinico San Borja-Arriaran, Santiago, Chile; M. Färkkilä, University Central Hospital, Helsinki, Finland; G. M. Fugarolas, J. F. deDios, Hospital Universitario Reina Sofia, Cordoba, Spain; A. Giacosa, Instituto Nazionale Per La Ricerca Sul Cancro, Genova, Italy; M. J. Goldstein, Long Island Gastro Intestinal Research Group, Great Neck, New York; F. Gomollon-Garcia, Hospital Universitario Miguel Servet, Zaragoza, Spain; P. Gandrup, Aalborg Syenhus, Aalborg, Denmark; A. HabrGama, Hospital das Clinicas da Faculdade de Medicina da Universidade de Sao Paulo, Sao Paulo, Brazil; C. Hall, University Hospital of North Staffordshire, Stoke on Trent, England; M. Haque, S. Parry, Middlemore Hospital, Auckland, New Zealand; R. Hardi, Metropolitan Gastroenterology Group, Chevy Chase, Maryland; W.
Harford, VA Medical Center, Dallas, Texas; S. M. Harris, N. B. Vakil, Aurora Sinai Medical Center, Milwaukee, Wisconsin; P. R. Holt, D. P. Kotler, Saint Luke's-Roosevelt Hospital, New York, New York; P. A. Holt, Endoscopic Microsurgery Associates, Towson, Maryland; R. W. Hultcrantz, Karolinska Universitetssjukhuset-Solna, Stockholm, Sweden; S. H. Itzkowitz, Mount Sinai Medical Center, New York, New York; R. F. Jacoby, University of Wisconsin Medical School, H6/516 C.S.C., Madison, Wisconsin; K. E. J. Jensen, Centralsygehuset Esbjerg Varde, Esbjerb, Denmark; J. F. Johanson, Rockford Gastroenterology Associates, Ltd, Rockford, Illinois; P. W. Jørgensen, Bispebjerg Hospital, Copenhagen, Denmark; K. E. Kim, University of Chicago Medical Center, Chicago, Illinois; P. Knoflach, AKH barmh, Schwestern vom helligen Kreuz, Wels, Austria; M. Koch, Capital Gastroenterology Consultants, Silver Spring, Maryland; B. Koch, St. Vincenz Krankenhaus, Datteln, Germany; A. Lanas, University Clinical Hospital, Zaragoza, Spain; M. R. Lane, Auckland City Hospital, Auckland, New Zealand; T. R. Liebermann, Radiant Research, Austin, Texas; M. Lukas, Univerzita Karlova, Charles University, Prague, Czech Republic; C. M. Schmitt, Southern Clinical Research, Chattanooga, Tennessee; F. Macrae, Cabrini Hospital, Malvern, Australia; E. E. Maiza, Hospital Jose Joaquin Aguirre, Santiago, Chile; N. E. Marcon, Toronto, Canada; R. D. Marks, Alabama Digestive Research Center, Alabaster, Alabama; C. E. Martinez, Hospital Militar Central, Bogota, Colombia; R. McLeod, Mount Sinai Hospital, Toronto, Canada; K. R. McQuaid, VA Medical Center, San Francisco, California; G. Minoli, Ospedale Valduce Reparto, Como, Italy; N. Mirza, University of Birmingham, Birmingham, England; M. Montoro, Hospital San Jorge, Huesca, Spain; A. Montoya, Clinica Shaio, Bogota, Colombia; G. Morelli, Optimum Clinical Research, Inc, Montreal, Canada; D. G. Morton, Queen Elizabeth Hospital, Edgbaston, England; T. J. Myrhoj, J. R. Andersen, Hvidovre Hospital, Hvidovre, Denmark; A. Nakad, Hospital Notre Dame, Tournai, Belgium; V. Narayen, Gastrointestinal Diagnostic Center, Baltimore, Maryland; Y. Niv, Rabin Medical Center, Petah Tikva, Israel; P. M. Pardoll, S. Scheinert, Center for Digestive Diseases, St. Petersburg, Florida; C. Phino, J. M. Soares, Celestial Ordem Terceira da Santissima, Porto, Portugal; I. Pokorny, Prerov, Czech Republic; J. Ponce-Garcia, Hospital Universitari La Fe Valencia, Valencia, Spain; T. Ponchon, Hospital Edouard Herriot, Lyon, France; J. H. Pressman, San Diego Digestive Disease Consultants, Inc., San Diego, California; V. Prochazka, Fakultni Nemocnice Olomouc, Olomouc, Czech Republic; J. M. Provenza, Louisiana Research Center, Shreveport, Louisiana; W. S. Putnam, Seattle Gastroenterology Associates, Seattle, Washington; E. Quintero-Carrion, Hospital Universitario De Canarias Tenerife, Santa Cruz de Tenerife, Spain; S. Radley, University Hospital Birmingham, Birmingham, England; J. P. Raufman, V. Raj, University of Arkansas for 
Medical Sciences, Little Rock, Arkansas; D. K. Rex; Indiana University Hospital, Indianapolis, Indiana; F. P. Rossini, M. Spandre, Azienda Sanitaria Ospedaliera, Torino, Italy; R. I. Rothstein, Dartmouth Hitchcock Medical Center, Lebanon, New Hampshire; A. K. Rustgi, University of Pennsylvania, Philadelphia, Pennsylvania; R. Sandler, University of North Carolina at Chapel Hill, Chapel Hill, North Carolina; B. Schmeizer, Sunninghill Clinic, Sandton, South Africa; R. E. Schoen, UPMC Presbyterian Department of Medicine, Pittsburgh, Pennsylvania; T. T. Schubert, Allenmore Medical Center, Tacoma, Washington; H. I. Schwartz, Miami Research Associates, Miami, Florida; E. Segal, Hospital General de Agudos Carlos G. Durand, Buenos Aires, Argentina; F. SeowChoen, K. W. Eu, Singapore General Hospital, Singapore; N. R. Shah, Philip J. Bean Medical Center, Hollywood, Maryland; N. Skandalis, Peripheral General Hospital, Athens, Greece; Y. Soon, University of Birmingham, Birmingham, England; P. L. Szego, Montreal, Canada; N. Toribara, University of Colorado Health Sciences Center, Denver, Colorado; J. Torosis, GI Research, Redwood City, California; D. K. Turgeon, University of Michigan, Ann Arbor, Michigan; S. W. Van der Merwe, Pretoria, South Africa; R. VanStolk, C. W. Howden, Northwestern University, Chicago, Illinois; P. Vergauwe, Algemeen Ziekenhuis Groeninge, Kortrijk Belgium; B. Vergeau, C. Nizou, Hopital d'Instruction des Armees, Paris, France; G. Winde, Klinikum Kreis Herford, Herford, Germany; J. Wolosin, M. W. Swaim, Regional Research Institute, Jackson, Tennessee; J. C. Wolper, P. L. Yudelman, Digestive Health Physicians, Fort Myers, Florida; B. C. Y. Wong, University of Hong Kong Queen Mary Hospital, Hong Kong; J. P. Wright, Kinsbury Hospital, Claremont, South Africa; A. Zambelli, Ospedale Maggiore Azienda Ospedaliera, Crema, Italy.

\section{References}

1. Hawkey CJ, Langman MJ. Non-steroidal anti-inflammatory drugs: overall risks and management. Complementary roles for COX-2 inhibitors and proton pump inhibitors. Gut 2003;52:600-608.

2. Lanza FL, Rack MF, Simon TJ, Quan H, Bolognese JA, Hoover ME, et al. Specific inhibition of cyclooxygenase-2 with MK-0966 is associated with less gastroduodenal damage than either aspirin or ibuprofen. Aliment Pharmacol Ther 1999;13:761-767.

3. Laine L, Harper S, Simon T, Bath R, Johanson J, Schwartz H, et al. A randomized trial comparing the effect of rofecoxib, a cyclooxygenase 2-specific inhibitor, with that of ibuprofen on the gastroduodenal mucosa of patients with osteoarthritis. Rofecoxib Osteoarthritis Endoscopy Study Group. Gastroenterology 1999;117: 776-783.

4. Hawkey CJ, Laine L, Simon T, Quan H, Shingo S, Evans J, et al. Incidence of gastroduodenal ulcers in patients with rheumatoid arthritis after 12 weeks of rofecoxib, naproxen, or placebo: a multicentre, randomised, double blind study. Gut 2003;52:820826.

5. Hunt RH, Harper S, Watson DJ, Yu C, Quan H, Lee M, Evans JK, Oxenius B. The gastrointestinal safety of the COX-2 selective inhibitor etoricoxib assessed by both endoscopy and analysis of upper gastrointestinal events. Am J Gastroenterol 2003;98:1725-1733.

6. Bombardier C, Laine L, Reicin A, Shapiro D, Burgos-Vargas R, Davis $B$, et al. Comparison of upper gastrointestinal toxicity of rofecoxib and naproxen in patients with rheumatoid arthritis. VIGOR study group. N Engl J Med 2000;343:1520-1530.

7. Schnitzer TJ, Burmester GR, Mysler E, Hochberg MC, Doherty M, Ehrsam E, et al. Comparison of lumiracoxib with naproxen and ibuprofen in the Therapeutic Arthritis Research and Gastrointestinal Event Trial (TARGET), reduction in ulcer complications: randomised controlled trial. Lancet 2004;364:665-674.

8. Silverstein FE, Faich G, Goldstein JL, Simon LS, Pincus T, Whelton A, et al. Gastrointestinal toxicity with celecoxib vs nonsteroidal anti-inflammatory drugs for osteoarthritis and rheumatoid arthritis: the CLASS study: a randomized controlled trial. Celecoxib Long-term Arthritis Safety Study. JAMA 2000;284:1247-1255.

9. Singh G, Fort JG, Goldstein JL, Levy RA, Hanrahan PS, Belo AE, et al. Celecoxib versus naproxen and diclofenac in osteoarthritis patients. SUCCESS-I study. Am J Med 2006;119:255-266.

10. Bresalier RS, Sandler RS, Quan H, Bolognese JA, Oxenius B, Horgan $\mathrm{K}$, et al. Cardiovascular events associated with rofecoxib in a colorectal adenoma chemoprevention trial. N Engl J Med 2005;352:1092-1102.

11. Bresalier RS, Sandler RS, Bolognese J, Quan H, Oxenius B, Joseph $\mathrm{R}$, et al. A randomized trial of rofecoxib to prevent colorectal adenomas: the Approve trial. Gastroenterology 2005 128(Suppl 2):200, A-35.

12. Watson DJ, Harper SE, Zhao PL, Quan H, Bolognese JA, Simon TJ. Gastrointestinal tolerability of the selective cyclooxygenase-2 (COX-2) inhibitor rofecoxib compared with nonselective COX-1 and COX-2 inhibitors in osteoarthritis. Arch Intern Med 2000; 160:2998-3003.

13. Thal LJ, Ferris SH, Kirby L, Block GA, Lines CR, Yuen E, Assaid C, Nessly ML, Norman BA, Baranak CC, Reines SA. A randomized, double-blind, study of rofecoxib in patients with mild cognitive impairment. Neuropsychopharmacology 2005;30:1204-1215.

14. Laine L, Bombardier C, Hawkey CJ, Davis B, Shapiro D, Brett C, Reicin A. Stratifying the risk of NSAID-related upper gastrointestinal clinical events: results of a double-blind outcomes study in patients with rheumatoid arthritis. Gastroenterology 2002;123:1006-1012.

15. Kaufman DW, Kelly JP, Wiholm BE, Laszlo A, Sheehan JE, Koff $\mathrm{RS}$, et al. The risk of acute major upper gastrointestinal bleeding among users of aspirin and ibuprofen at various levels of alcohol consumption. Am J Gastroenterol 1999;94:3189-3196.

16. Garcia Rodriguez LA, Cattaruzzi C, Trocon MG, Agostinis L. Risk of hospitalization for upper gastrointestinal tract bleeding associated with ketorolac, other nonsteroidal anti-inflammatory drugs, calcium antagonists, and other antihypertensive drugs. Arch Intern Med 1998;158:33-39.

17. Holvoet J, Terriere L, Van Hee W, Verbist L, Fierens E, Hautekeete $\mathrm{ML}$. Relation of upper gastrointestinal bleeding to non-steroidal anti-inflammatory drugs and aspirin: a case-control study. Gut 1991;32:730-734.

18. Schefer Al. Effects of nonsteroidal antiinflammatory drugs on platelet function and systemic hemostasis. J Clin Pharmacol 1995;35:209-219.

19. Silverstein FE, Graham DY, Senior JR, Davies HW, Struthers BJ, Bittman RM, et al. Misoprostol reduces serious gastrointestinal complications in patients with rheumatoid arthritis receiving nonsteroidal anti-inflammatory drugs. A randomized, double-blind, placebo-controlled trial. Ann Intern Med 1995;123:241-249.

Received May 4, 2006. Accepted October 12, 2006.

Address requests for reprints to: Angel Lanas, MD, Gastroenterology Service, University Hospital, 50009 Zaragoza, Spain. e-mail: alanas@ posta.unizar.es; fax: (34) 976762539 .

Supported by Merck Research Laboratories.

The authors are indebted to the study subjects for their cooperation and enthusiasm. 